\title{
Morphological characteristics of male germ cells of rats in contact with Sertoli cells in vitro
}

\author{
F. Palombi, E. Ziparo, F. F. G. Rommerts*, J. A. Grootegoed*, \\ M. Antonini and M. Stefanini
}

Institute of Histology and General Embryology, School of Medicine, University of Rome, Italy, and ${ }^{*}$ Department of Biochemistry (Division of Chemical Endocrinology), Medical Faculty, Erasmus University, Rotterdam, The Netherlands

\begin{abstract}
Summary. Fragments of seminiferous epithelium were prepared from 3-week-old rats. Although the Sertoli cells formed a monolayer, germ cells (spermatogonia and early spermatocytes) remained in association with them and were of normal ultrastructural appearance. Germ cells became completely separated from Sertoli cells after 3 weeks of culture in a chemically defined medium. The contact areas between Sertoli and germ cells were characterized by desmosome-like junctions while those between germ cells appeared to be pentalaminar.
\end{abstract}

\section{Introduction}

In recent years, cultures of isolated Sertoli cells have been used to investigate functional properties of this cell type and its possible role in regulating spermatogenesis (Tung, Dorrington \& Fritz, 1975; Dorrington \& Armstrong, 1975; Dorrington, Roller \& Fritz, 1975; Fritz et al., 1975; Fritz, Rommerts, Louis \& Dorrington, 1976; Tung \& Fritz, 1977). So far the characterization of such Sertoli cell cultures has mainly concerned the response of specific Sertoli cell parameters to hormonal stimulation, and the interaction between Sertoli and germinal cells in vitro has hardly been investigated. However, a constant feature of Sertoli cell-enriched cultures is represented by the presence of associated germinal cells (Fritz et al., 1975; Stefanini, Palombi, Ziparo \& Antonini, 1978).

Male germ cells have been shown to survive and undergo various degrees of differentiation in organ culture (Steinberger \& Steinberger, 1966a, 1967; Ghatnekar, Lima De Faria, Rubin \& Menander, 1974), and in cultures of seminiferous tubules (Eddy \& Kahri, 1976). Isolated spermatocytes cannot survive for very long in simple culture media; incorporation of uridine into RNA decreases after approximately $20 \mathrm{~h}$ (Grootegoed, Grolle-Hey, Rommerts \& van der Molen, 1977).

Somatic cells may somehow play an essential role in germ cell survival in vitro, but no definition of such an interaction has been made available from the experimental models described so far.

The present paper describes the ultrastructural characteristics of germ cells with only Sertoli cells as other testicular component after incubation periods of up to 3 weeks in a chemically defined culture medium.

\section{Materials and Methods}

\section{Cell preparation}

The procedure followed was that described by Dorrington et al. (1975), slightly modified. Testes from 20-day-old rats were collected in Hanks' buffer. The tunica albuginea was removed and the tissue was cut into $0.45 \mathrm{~mm}$ thick slices by a tissue sectioner (Sorvall TC-2). Testicular fragments were then digested at $32^{\circ} \mathrm{C}$ in $50 \mathrm{ml} \mathrm{Hanks}$ ' buffer containing $0.25 \%$ trypsin (Difco 
$1: 250$ ) and $10 \mu \mathrm{g}$ DNAase (type 1 , Boehringer) $/ \mathrm{ml}$. After incubation at $32^{\circ} \mathrm{C}$ for $30 \mathrm{~min}$ (shaking at 60 oscillations/min), bovine fetal serum was added (final concentration $2 \%$ ) to inhibit the enzymic activity. The seminiferous tubules were washed several times with Hanks' buffer and then digested with collagenase ( $1 \mathrm{mg} / \mathrm{ml}$ : Boehringer, Grad II) in $20 \mathrm{ml} \mathrm{Hanks'} \mathrm{buffer}$ for $30 \mathrm{~min}$. The tubular fragments were harvested by low-speed centrifugation $(75 \mathrm{~g})$, washed twice with Hanks' buffer, and then dispersed by gentle agitation with a Pasteur pipette (10-12 passages in the pipette) with $\mathrm{Ca}^{2+}$ and $\mathrm{Mg}^{2+}$-free phosphate-buffered saline, $\mathrm{pH} 7 \cdot 2$. The fragments, of approximately $250 \mu \mathrm{m}$ in length, were harvested by low-speed centrifugation $(75 \mathrm{~g}$ ) and resuspended in culture medium ( $1 \mathrm{ml}$ medium for each $0.1 \mathrm{ml}$ tissue aggregates).

The culture medium consisted of Eagle's minimal essential medium (Microbiological Associates) supplemented with antibiotics and non-essential amino acids, as in Medium A of Steinberger \& Steinberger (1966b) with the exceptions that the final glutamine concentration was $4 \mathrm{~mm}$ and no sodium pyruvate was present. No serum was added to the culture medium.

\section{Culture conditions}

Three to four drops of the suspension were plated with a $1 \mathrm{ml}$ pipette into a $25 \mathrm{~cm}^{2} \mathrm{Falcon}$ polystyrene flask or into a $60 \mathrm{~mm}$ Falcon polystyrene Petri dish both containing $5 \mathrm{ml}$ medium. The density was approximately $10^{4}$ aggregates per vessel. Incubation was carried out at $32^{\circ} \mathrm{C}$ in a water-saturated atmosphere of $95 \%$ air and $5 \% \mathrm{CO}_{2}$. The medium, together with any cells that were not attached, was removed $24 \mathrm{~h}$ later, and $5 \mathrm{ml}$ fresh culture medium was added. The medium was then changed at 6-day intervals and incubations were continued for various periods. FSH ( $5 \mu \mathrm{g}$ NIAMDD-rat-FSH-B 1 or NIAMDD-ovine-FSH/ml) or dibutyryl cyclic AMP $(0.1 \mathrm{mM})$ were added to the culture at the first change of medium.

\section{Morphological techniques}

Culture flasks were periodically examined and photographed with a Leitz Diavert inverted microscope equipped with phase-contrast optics. Additional observations on unfixed material were performed on microscope slide cultures, with a Zeiss photomicroscope II equipped with a Nomarski differential interference-contrast apparatus. The percentage of dead cells at the different culture times was evaluated by trypan blue staining. At various culture times sample fixation was performed by adding $1 \%$ glutaraldehyde in $0.1 \mathrm{M}$-sodium cacodylate buffer directly into the culture vessel. After post-fixation with $1 \% \mathrm{OsO}_{4}$ in Zetterqvist buffer (Zetterqvist, 1956) and alcohol dehydration, large fragments of the cellular monolayer were detached from the plastic vessel by the transitional solvent (propylene oxide or toluene) being used between the dehydrating agent and the embedding mixture. The sample was washed with several changes of propylene oxide or toluene to remove the dissolved plastic of the culture vessel. The pelleted fragments of the cellular monolayer were embedded in Epon 812. Thick sections $(1 \mu \mathrm{m})$ were stained with buffered toluidine blue for light microscope examinations. Contrast was enhanced in thin sections by staining in a saturated solution of uranyl acetate in water followed by lead citrate (Venable \& Coggeshall, 1965). Thin sections were examined in a Siemens Elmiskop 101 electron microscope.

Evaluation of the percentage of germ cells involved semithin sections of pellets of isolated cells, obtained by treatment with $0.025 \%$ trypsin (Difco $1: 250$ ) and $0.012 \%$ EDTA in $\mathrm{Ca}^{2+}$ and $\mathrm{Mg}^{2+}$-free phosphate-buffered saline. Cell counts for control and FSH-stimulated samples were performed in 5 experiments at different times between Days 3 and 15. For each evaluation cells from 2 different culture vessels were pooled, and a minimum of 500 cells was counted.

\section{Results}

Germ cell positioning in the culture. During the first 3-4 days of culture, Sertoli cells migrated away from the explants and formed a monolayer of flattened cells (Pl. 1, Fig. 1) which was 

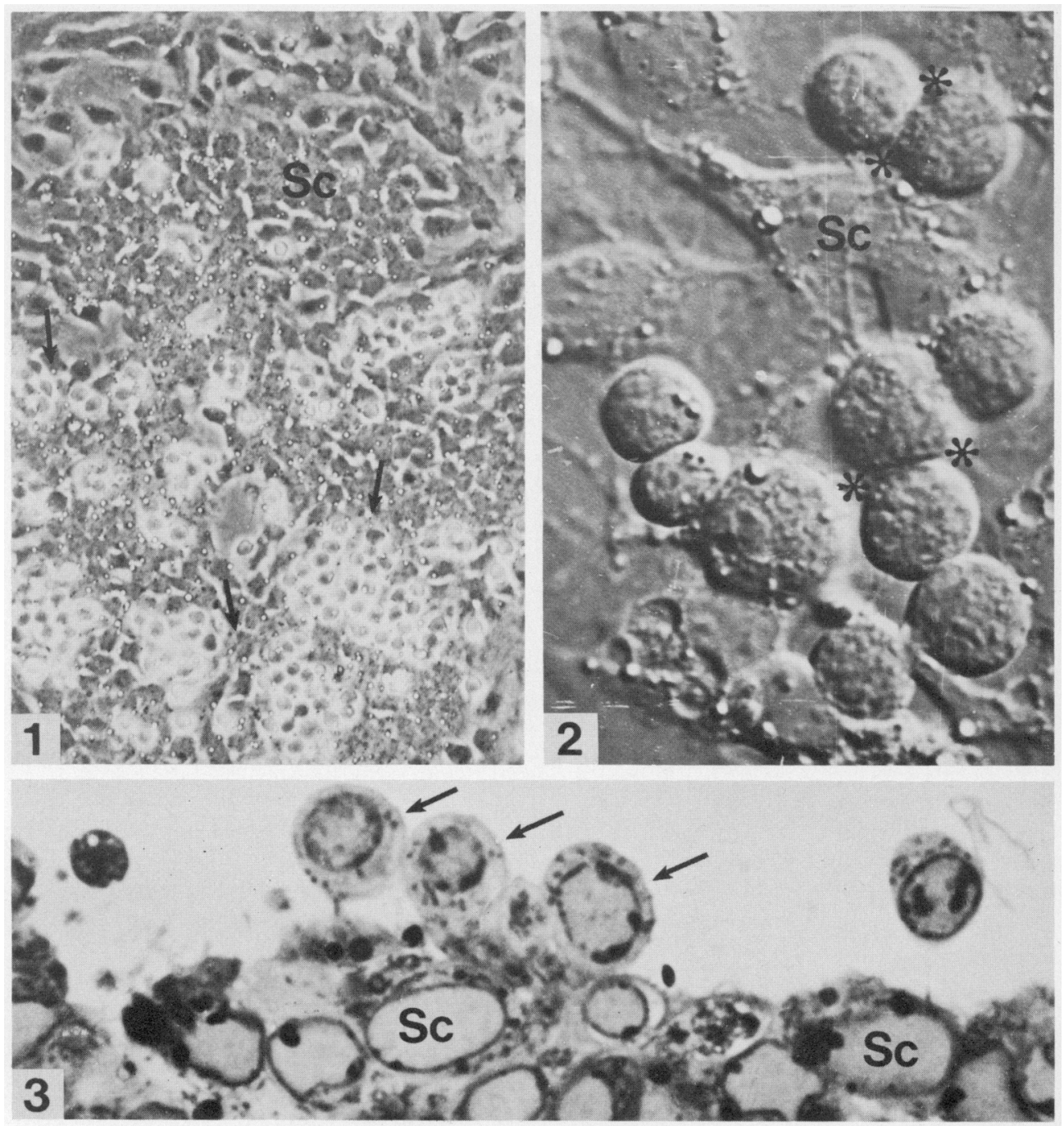

Figs 1-3. These figures illustrate germ cell positioning in 4-day cultures. Once the Sertoli cells (Sc) have formed a monolayer, on a higher plane of focus a second cell population is observable (Fig. 1, arrows). These cells are round, often arranged in clusters, and flattened one against the other (Fig. 2, asterisks). In semithin sections tangential or perpendicular to the monolayer (Fig. 3 ) the cells positioned on the higher level (arrows) are recognizable as germ cells. Fig. 1, phase microscopy, $\times 180$; Fig. 2, Nomarski differential interference-contrast, $\times 1100$; Fig. 3, semithin section, $\times 1500$. 
PLATE 2

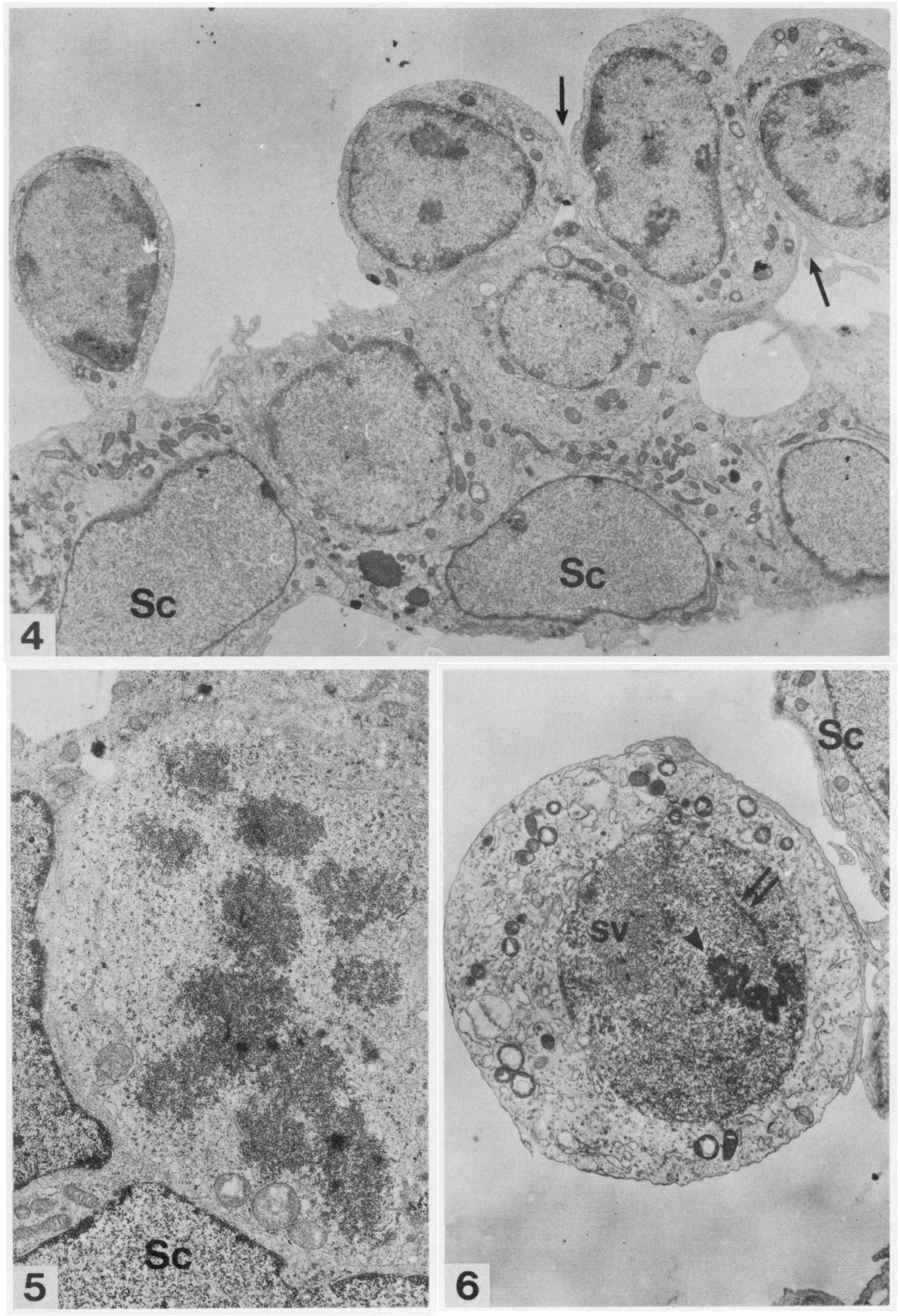


PLATE 3

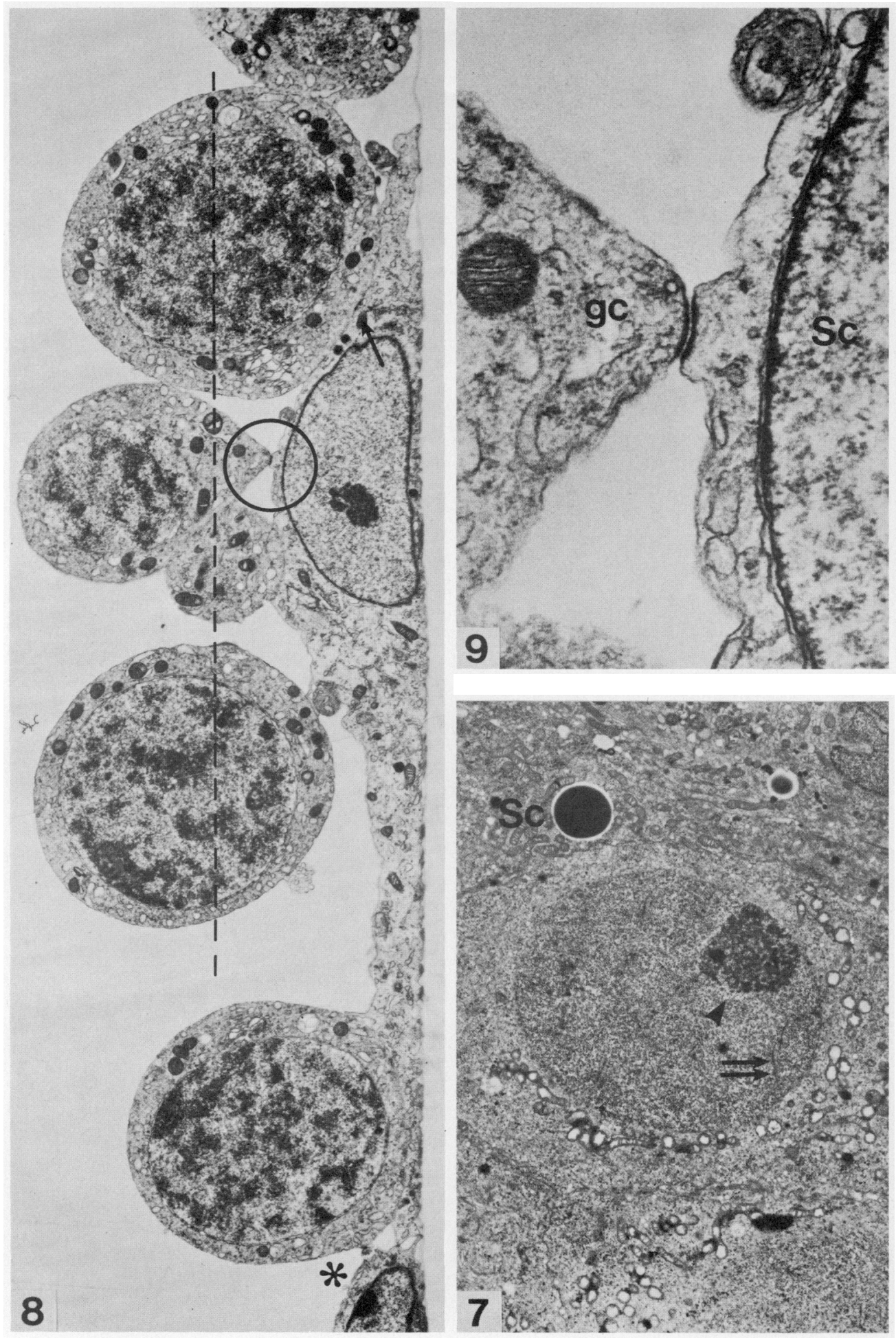




\section{PLATE 4}

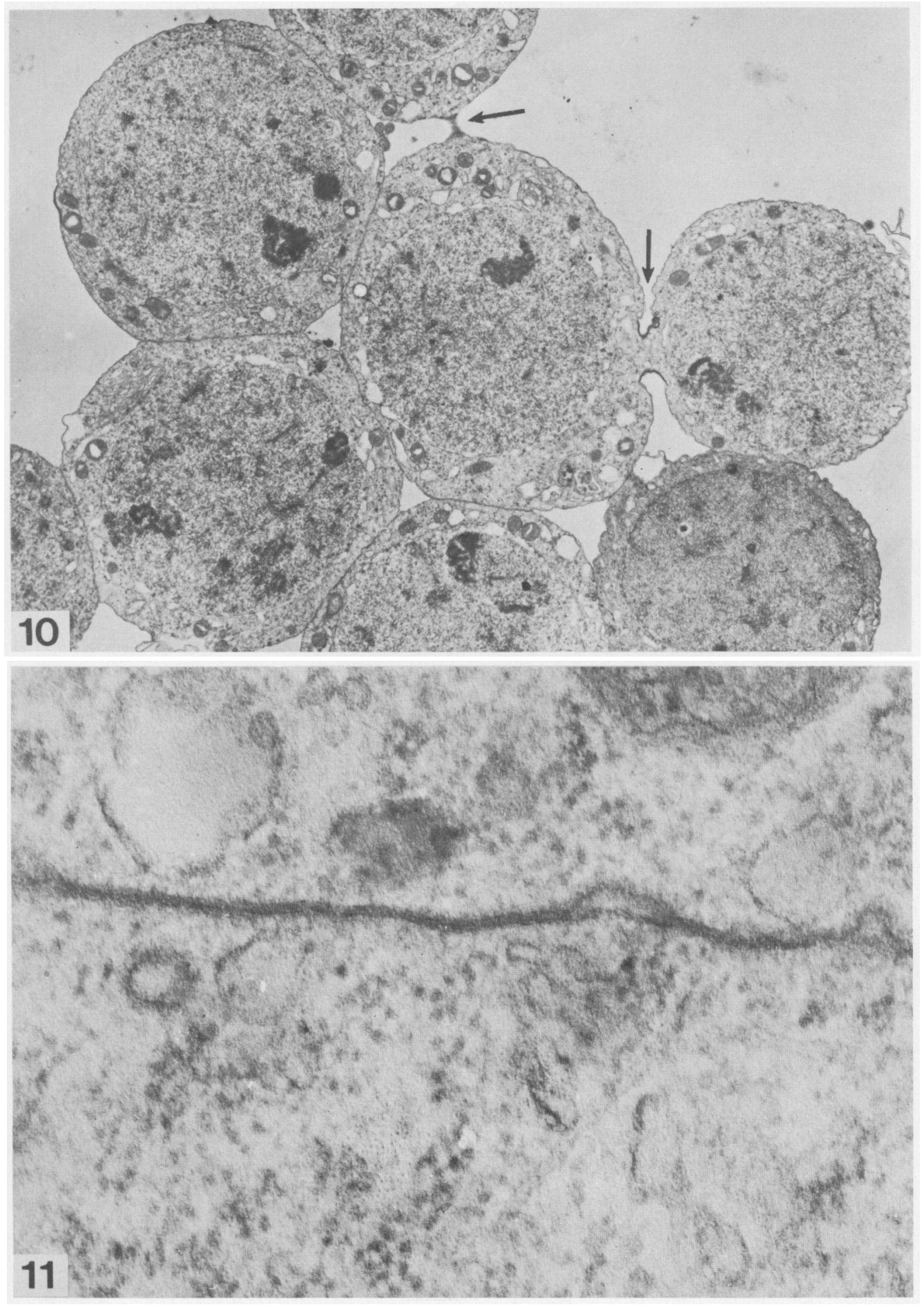


overlain by germ cells (Pl. 1, Figs 1 and 2). These cells were round, unequally distributed and often arranged in large clusters. As shown by trypan blue staining, only few (up to $10 \%$ ) degenerating germ cells were observed at each day of culture.

Germ cell characterization and quantitation. The germ cells could easily be identified in semithin sections: most were spermatogonia and early spermatocytes (Pl. 1, Fig. 3). The initial amount of germ cells present in the culture varied in different experiments, their loss depending on the degree of traumatization, the size of the tubular explants plated (Tung \& Fritz, 1977), and the density of plating, which also influences the rate of Sertoli cell outgrowth and thus the numbers of germ cells that remain enclosed among the Sertoli cells. The quantitative variations of germ cell population therefore had to be considered within each experiment. Once Sertoli cells had outgrown from the initial explants up to $25 \%$ germ cells were found in association with the monolayer; this population was reduced to half the initial values at the end of the first week of culture, and up to one-third at the end of the second week. Complete separation between the Sertoli and germ cells required up to 3 weeks.

Ultrastructural analysis showed that about $90 \%$ of the germ cells present at any one time had well preserved structures, and their submicroscopic features were comparable to those of germ cells in intact testes.

Type B spermatogonia were the most frequently encountered of this type of cell (P1. 2, Fig. 4). The nucleus was oval with a small fibrillo-granular nucleolus and clumps of condensed chromatin closely apposed to the inner nuclear membrane; the cytoplasm contained only a small amount of smooth endoplasmic reticulum and mitochondria with lamellar cristae. Metaphase spermatogonia were sometimes found even after 8 days of culture (Pl. 2, Fig. 5).

\section{PLATE 2}

Figs 4 and 5. Most of the spermatogonia present in the cultures are often of the B type. They are located on top of the monolayer (Fig. 4), partly surrounded by cytoplasmic laminae (arrows) of the Sertoli cells $(\mathrm{Sc})$. The presence of typical mitochondria and the few cytoplasmic organelles indicate that the cells undergoing division are spermatogonia (Fig. 5). Fig. 4, 5 days of culture; $\times 4200$. Fig. 5,8 days of culture, $\times 7600$.

Fig. 6. A zygotene spermatocyte on top of the Sertoli cell monolayer (SC) after 4 days of culture. Arrow head, nucleolus; double arrow, synaptonemal complex; SV, sex vesicle. $\times 5600$.

\section{PLATE 3}

Fig. 7. A pachytene spermatocyte on top of a Sertoli cell monolayer ( $\mathrm{Sc}$ ) after 3 days of culture. Arrow head, nucleolus; double arrow, synaptonemal complex. $\times 3800$.

Figs 8 and 9. Demonstration of the surface relationships between Sertoli cells and germ cells after culture for 4 days. In the contact areas between Sertoli and germ cells desmosome-like structures are present (arrow). The asterisk (Fig. 8) points to one of these structures that during tissue manipulation has induced the rupture of a fragment of the Sertoli cell. The desmosome-like structure encircled in Fig. 8 is enlarged in Fig. 9. Note the condensation of the cytoplasm and the faintly electron-dense material in the intervening space. Sc, Sertoli cell; gc, germ cell. Fig. 8, $\times 5600$; Fig. $9, \times 33000$.

\section{PLATE 4}

Figs 10 and 11. The plane of sectioning in Fig. 10 was parallel to the monolayer at the level of the germinal cells, as indicated by the dotted line in Fig. 8. A cluster of leptotene spermatocytes are connected by intercellular bridges (Fig. 10, arrows). The areas of direct contact are flattened, with the apposed membranes often fused (Fig. 11). In the fused areas pentalaminar junctional structures are observable. Fig. 10, 6 days of culture, $\times 5200$; Fig. 11,9 days of culture, $\times 103000$. 
At any culture time meiotic cells were mostly represented by leptotene spermatocytes, characterized by a high nucleus to cytoplasm ratio, absence of condensed chromatin, presence of chromosomal cores, small nucleolar structures, and a few mitochondria with one or more dilated cristae.

Meiotic cells at zygotene (Pl. 2, Fig. 6) and early pachytene (Pl. 3, Fig. 7) stages were also present and were identified by criteria such as the increase in cell volume and in cytoplasmic organelles, development of nucleoli, the presence of synaptonemal complexes, and of the sex vesicle.

Surface relationship between Sertoli cells and germ cells. During the first days of the culture period, the germ cells, still contained within the seminiferous epithelium, were individually surrounded by Sertoli cells. During the next few days, migration of the Sertoli cells resulted in drastic modifications of the architecture of the seminiferous epithelium which led to gradual modification of the Sertoli cell-germ cell contacts. While flattening, Sertoli cells retracted their laminar protrusions, thus uncovering wide areas of germ cell surface and reducing the contacts between the two cell types (Pl. 2, Figs 4 and 6; Pl. 3, Fig. 8; Pl. 4, Fig. 10). In the contact areas junctional specializations were observed, similar to those of the desmosome-like type (Pl. 3, Figs 8 and 9), described in vivo (Russell, 1977), in which reduction of the intervening space is sometimes apparent.

Within germ cell clusters, besides germ cell-Sertoli cell contacts, other intercellular relationships were observed. The cytoplasmic bridges normally connecting germ cells at the same stage of differentiation were still present (Pl. 4, Fig. 10) and new germ cell to germ cell membrane contacts were established. In fact, after retraction of the interposed Sertoli cell branches, germ cell surfaces became closely apposed along extended areas (Pl. 1, Fig. 2; Pl. 4, Fig. 10). At higher magnification, within these areas the apposed membranes were often seen to fuse (P1. 4, Fig. 11). These junctional specializations had a pentalaminar organization and varied in length up to $750 \mathrm{~nm}$.

Response to stimulation. Treatment by either FSH or dibutyryl cyclic AMP resulted in the formation of numerous cytoplasmic extensions by Sertoli cells, but there was no apparent effect on the germ cell population.

\section{Discussion}

The presence of germ cells in Sertoli cell-enriched cultures has been observed in short-term cultures (Fritz et al., 1975; Tung \& Fritz, 1977) and these cells may represent up to $10 \%$ of the entire cell population at the end of the first week of culture. Our data extend this information by demonstrating that germ cells survive in culture for even longer times, disappearing only by the end of the 3rd week of culture. Moreover, the germ cells that survive in short- and long-term Sertoli cell-enriched cultures comprise well-preserved cellular elements which are ultrastructurally similar to those of normal cells of this type. The prevalence of leptotene spermatocytes among meiotic cells, reflects the composition of the seminiferous epithelium in 3-week-old rats. Preliminary observations on Sertoli cell-enriched cultures from older animals indicate that pachytene spermatocytes do not undergo degeneration.

The well-preserved morphological characteristics of many germ cells in contact with Sertoli cells after culture periods of more than 5 days seems to be in contrast with the observations on the degeneration pattern of isolated pachytene spermatocytes in a simple culture medium, i.e. the decreased RNA synthesis after 1 (Grootegoed et al., 1977) and 5 days ( $<5 \%$ of original activity: J. A. Grootegoed, unpublished observations) and the early onset of morphological deterioration. It therefore seems possible that, in our experimental conditions, the association with the Sertoli cells is responsible for germ cell survival. Such an interaction could be mediated by surface contacts and/or Sertoli cell secretion products.

The relevance of direct contact between Sertoli cells and germ cells for survival in vitro is 
difficult to evaluate, since the localized junctional structures observed between germ cells and Sertoli cells (Pl. 3, Figs 8 and 9) are not of the kind supposed to have an informational meaning, although the functional properties of junctional structures are still matter of debate.

During outgrowth of the explants, flattening of the Sertoli cells is accompanied by local disruption of the Sertoli cell junctions. This permits the displacement of the germ cells from the basal compartment to the top of the Sertoli cell monolayer (Pl. 1, Figs 1 and 2). Spermatogenesis in vivo occurs inside the seminiferous tubules and it has been suggested (Setchell, 1974) that the specific composition of tubular fluid (Fawcett, 1974) is a requirement for normal development of germ cells. The results in this paper, however, show that germ cells can survive in culture when almost all of the germ cell membrane is in contact with the culture medium although the composition of this medium is completely different from that of tubular fluid. This suggests that a specific tubular microenvironment is not required for early germ cell survival, but does not preclude requirement for all the compounds present in seminiferous fluid for complete maturation of germ cells.

Although Sertoli cell flattening brings about uncovering of most of the germ cell surface, the persistence of desmosome-like junctions in the remaining contact areas appears to be responsible for the firm attachment of germ cells to the underlying Sertoli cells. Of particular interest are the areas of germ cell to germ cell contact (Pl. 4, Figs 10 and 11). These junctional specializations have not been described previously (and would not occur in vivo because interdigitating protrusions of Sertoli cells prevent direct contact of germ cells) and they are difficult to classify. Direct contact between the germ cells occurs only after a few days in culture, and so the possibility that junction formation results from previous enzymic treatment of the seminiferous tubules can be ruled out. The unusual extension of the fused tracts observed in thin sections suggests that such contacts do not follow a linear profile, but are extended to unusually broad areas within the two flattened contacting membranes. It is difficult to attribute any functional role to these unusual junctions, besides that of contributing mechanically to cell maintenance in situ. Retraction of the Sertoli cell protrusions apparently caused a great reduction in the number of germ cells directly in contact with the monolayer but the maintenance of cytoplasmic bridges as well as the formation of germ cell to germ cell adhesion areas clearly assisted the maintenance of large clusters of germ cells in culture.

This work was supported by CNR project "Biology of reproduction", contract no. 76.00300 .85 , by Ford Foundation grant No. 730.02 .08 , and by N.A.T.O. grant no. 1064. We are indebted to the NIAMDD rat pituitary hormone distribution program and to $\mathrm{Dr} \mathrm{A}$. F. Parlow for providing the FSH for this study.

\section{References}

Dorrington, J.H. \& Armstrong, D.T. (1975) Follicle stimulating hormone stimulates estradiol-17 $\beta$ synthesis in cultured Sertoli cells. Proc. natn. Acad. Sci. U.S.A. 72, 2677-2681.

Dorrington, J.H., Roller, N.F. \& Fritz, I.B. (1975) Effects of follicle-stimulating hormone on cultures of Sertoli cell preparations. Molec. cell. Endocr. 3, 59-70.

Eddy, E.M. \& Kahri, A.I. (1976) Cell associations and surface features in cultures of juvenile rat seminiferous tubules. Anat. Rec. 185, 333-358.

Fawcett, D.W. (1974) Interactions between Sertoli cells and germ cells. In Male Fertility and Sterility, pp. 13-36. Eds R. E. Mancini \& L. Martini. Academic Press, London.

Fritz, I.B., Louis, B.G., Tung, P.S., Griswold, M.D.,
Rommerts, F.F.G. \& Dorrington, J.H. (1975) Biochemical responses of cultured Sertoli cellenriched preparations to follicle stimulating hormone and dibutyryl cyclic AMP. In Hormonal Regulation of Spermatogenesis, pp. 367-382. Eds F. S. French, V. Hansson, S. N. Nayfeh \& E. M. Ritzén. Plenum Press, New York.

Fritz, I.B., Rommerts, F.F.G., Louis, B.G. \& Dorrington, J.H. (1976) Regulation by FSH and dibutyryl cyclic AMP of the formation of androgenbinding protein in Sertoli cell-enriched cultures. $J$. Reprod. Fert. 46, 17-24.

Ghatnekar, R., Lima de Faria, A., Rubin, S. \& Menander, K. (1974) Development of human meiosis in vitro. Hereditas 78, 265-271. 
Grootegoed, J.A., Grolle-Hey, A.H., Rommerts, F.F.G. \& van der Molen, H.J. (1977) Ribonucleic acid synthesis in vitro in primary spermatocytes isolated from rat testis. Biochem. $J$. 168, 23-31.

Russell, L. (1977) Desmosome-like junctions between Sertoli and germ cells in the rat testis. Am. J. Anat. 148, 301-312.

Setchell, B.P. (1974) The entry of substances into the seminiferous tubules. In Male Fertility and Sterility, pp. 37-57. Eds R. E. Mancini \& L. Martini. Academic Press, London.

Stefanini, M., Palombi, F., Ziparo, E. \& Antonini, M. (1978) In Discussion of paper by P. S. Tung \& I. B. Fritz: Histopathological changes in testes of adult inbred rats immunized against pachytene spermatocytes or Sertoli cells. Int. J. Androl., Suppl. 2, 479481.

Steinberger, A. \& Steinberger, E. (1966a) Stimulatory effect of vitamins and glutamine on the differentiation of germ cells in rat testes organ culture grown in chemically defined media. Expl Cell Res. 44, 429435.
Steinberger, A. \& Steinberger, E. (1966b) In vitro culture of rat testicular cells. Expl Cell Res. 44, 443-452.

Steinberger, A. \& Steinberger, E. (1967) Factors affecting spermatogenesis in organ cultures of mammalian testes. J. Reprod. Fert., Suppl. 2, 117-124.

Tung, P.S., Dorrington, J.H. \& Fritz, I.B. (1975) Structural changes induced by follicle-stimulating hormone or dibutyryl cyclic AMP on presumptive Sertoli cells in culture. Proc. natn. Acad. Sci. U.S.A. 72, 1838-1842.

Tung, P.S. \& Fritz, I.B. (1977) Isolation in culture of testicular cells: a morphological characterization. In Techniques of Human Andrology, pp. 125-143. Ed. E. S. E. Hafez. Elsevier/North Holland Biomedical Press, Amsterdam.

Venable, J.H. \& Coggeshall, R. (1965) A simplified lead citrate stain for use in electron microscopy. $J$. Cell Biol. 25, 407-408.

Zetterqvist, H. (1956) The ultrastructural organization of the columnar absorbing cells in the mouse jejunum. Thesis, Anatomy Dept., Karolinska Institute, Stockholm.

Received 11 December 1978 